\title{
Using Data of Control Public Points for Obtaining Values of Speeds on Ribs of the Roads
}

\author{
Alexey Borovskoy ${ }^{1 *}$, Alexandr Lukyanov ${ }^{1}$, Olga Borovskaya ${ }^{1}$, and Andrey Kravchenko ${ }^{1}$ \\ ${ }^{1}$ Belgorod State Technological University named after V.G. Shukhov, 46 Kostyukova str., Belgorod, \\ 308012, Russia
}

\begin{abstract}
A new developed scheme of public transport of the Belgorod agglomeration was introduced into the GIS system. This system allows to create a complete graph of roads with directions of public transport, as well as various information necessary to compile a full database. The data of dispatching points of public transport for obtaining velocity values on the edges of the graph of the roads of the city roads was surveyed.
\end{abstract}

\section{Introduction}

In connection with the development of a new scheme of public transport in Belgorod, there was a need for an accurate description of the road graph according to which the movement of public transport is already being carried out, and its movement is expected. Based on data from OpenStreetMap [1], traffic signs and road markings, traffic management projects and general plans, NextGIS QGIS [2] formed a single graph of the roads of the Belgorod agglomeration, which has the following form (fig. 1).

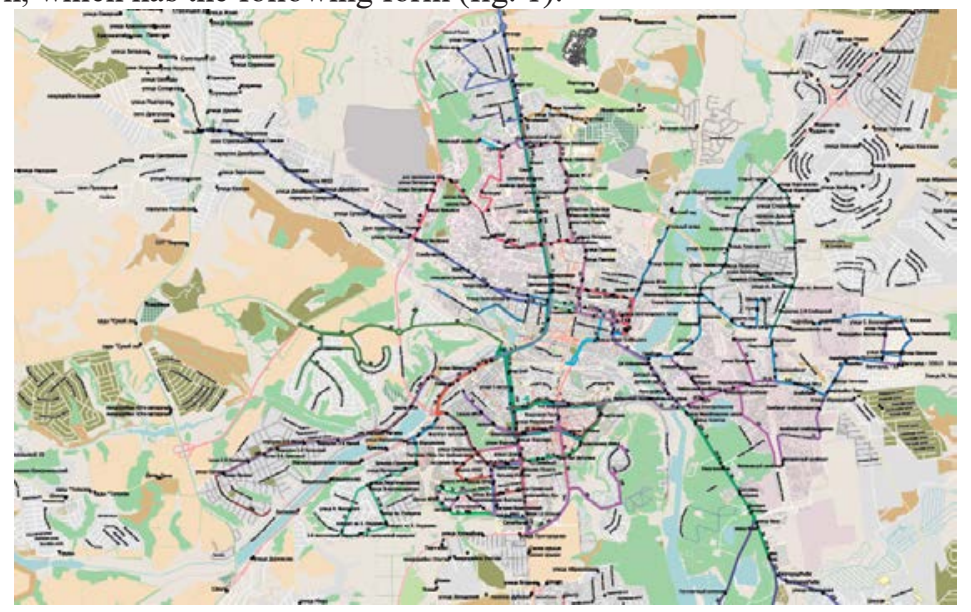

Fig. 1. New scheme of public transport of Belgorod agglomeration.

* Corresponding author: a.e.borovskoy@gmail.com 


\section{Theory}

The requirements for the graph are presented in the form of the following table [3].

Table 1. The main layers needed to build a road graph.

\begin{tabular}{|l|l|l|}
\hline Layer name & $\begin{array}{l}\text { Kind of graphic } \\
\text { primitive }\end{array}$ & \multicolumn{1}{c|}{ Appointment layer } \\
\hline $\begin{array}{l}\text { "Territories of } \\
\text { human } \\
\text { settlements" }\end{array}$ & Area (polygon) & $\begin{array}{l}\text { The layer contains actual names and subordinates of } \\
\text { settlements - for the current year. Must contain the } \\
\text { main settlements, through which passes and which } \\
\text { adjoin one of its borders to the road graph. }\end{array}$ \\
\hline $\begin{array}{l}\text { "Borders of } \\
\text { administrative } \\
\text { entities" }\end{array}$ & Area (polygon) & $\begin{array}{l}\text { The boundary layer of administrative entities describes } \\
\text { the position of the borders and correlates with the } \\
\text { territories of populated areas as belonging to } \\
\text { administrative entities. }\end{array}$ \\
\hline $\begin{array}{l}\text { "Road } \\
\text { constructions" }\end{array}$ & $\begin{array}{l}\text { Point, line, } \\
\text { polygon }\end{array}$ & $\begin{array}{l}\text { The road structure layer contains all objects of road } \\
\text { structures through which the road graph passes, and } \\
\text { describes the actual position and dimensions of road } \\
\text { structures. }\end{array}$ \\
\hline «Road graph» & $\begin{array}{l}\text { Components of } \\
\text { the edges and } \\
\text { nodes - a point, a } \\
\text { polyline }\end{array}$ & $\begin{array}{l}\text { The graph of the road network contains topological } \\
\text { links of the edges and nodes (vertices), which are the } \\
\text { main types of objects of the road graph. }\end{array}$ \\
\hline
\end{tabular}

The received data from the GPS / GLONASS trackers to the dispatching system, in the case of the Belgorod agglomeration in the software of the firm "SHTRIKH", are graphically displayed as follows (fig. 2) [4].

Each of the tracks includes certain data, such as date, time, latitude and longitude, altitude, speed, number of satellites used, etc (fig. 3) [5].

As a result of data processing, the summary information is presented as a txt file for each of the routes.

Statistical processing and analysis of data recorded by the tracker on the parameters of the movement of vehicles allow us to evaluate a number of parameters necessary to optimize the timetable for the movement of public transport [6]. In particular, the following parameters can be used:

- time spent for boarding / disembarking passengers;

- the time required to overcome the entire length of the route;

- Interval of public transport for each route;

- speed of vehicles on road sections between control points (main intersections, stops, etc.). 


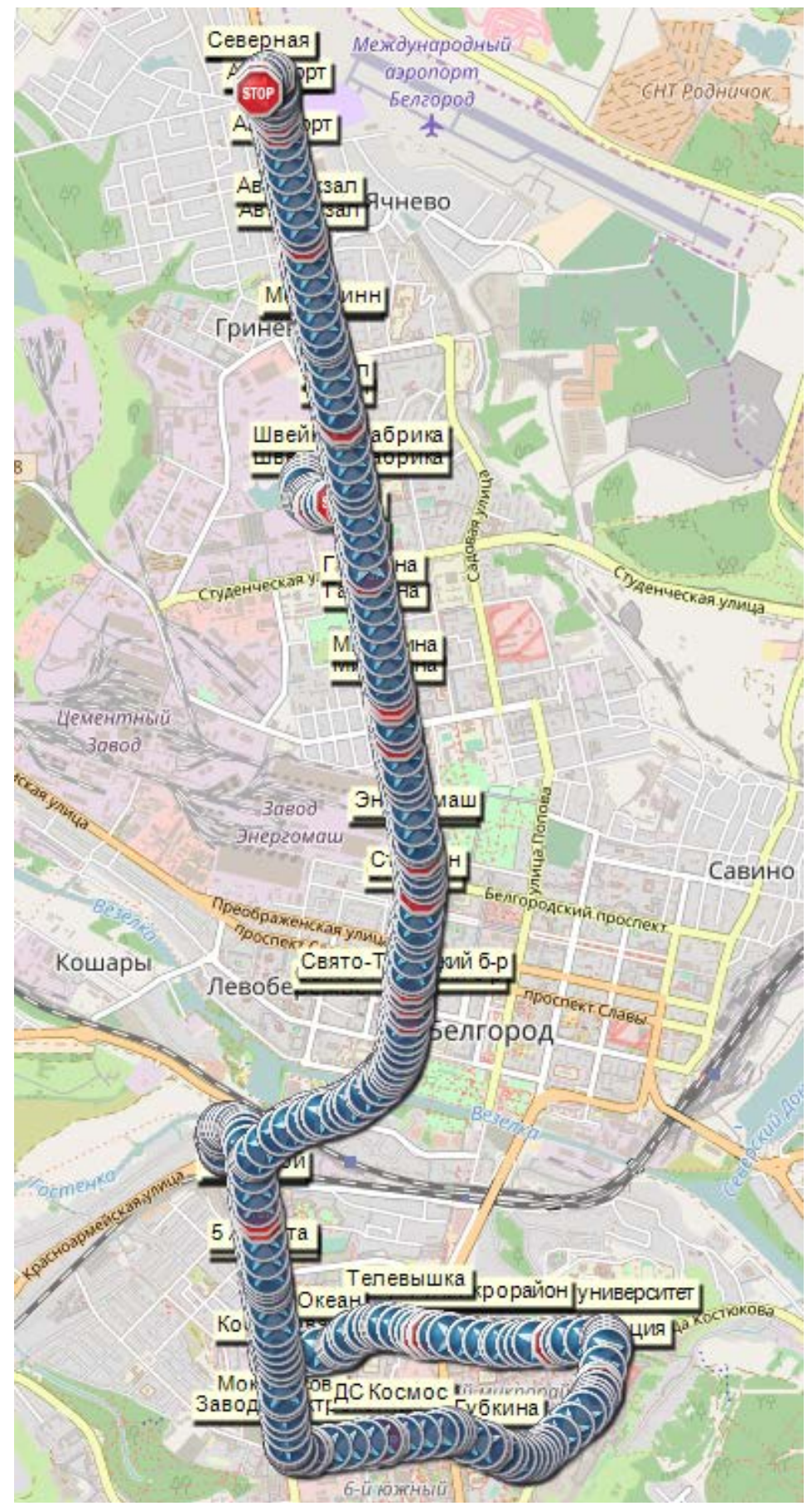

Fig. 2. Graphic display of the track of the public transport dispatching system of the firm "SHTRIKH". 


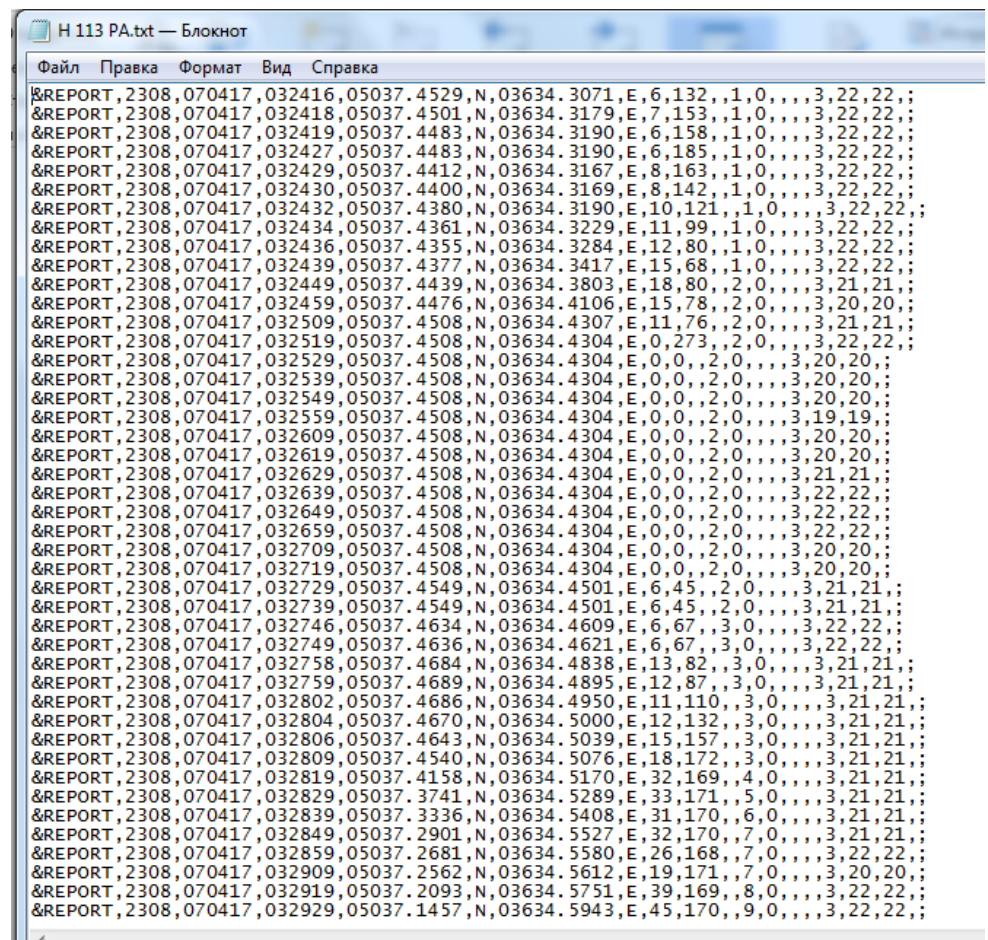

Fig. 3. Data received with GPS / GLONASS trackers.

Statistical processing of the generated parameters allows to determine their dependence on the time of day, day of the week and season [4,7].

\section{Results and Discussion}

1. The basis for evaluating all of the above parameters is the fixation of vehicle travel times for control points.

The moment of overcoming the control point is determined by the simultaneous fulfillment of two criteria: the achievement by the distance between the vehicle and the reference point of the minimum and the correspondence of the heading angle to the value set for this control point:

$$
\begin{aligned}
& \left\{\begin{array}{c}
\frac{d R(t)}{d t}=0 ; \\
\frac{d^{2} R(t)}{d t^{2}}>0 ; \\
\mid \text { Course }(t)-\text { Course_CP } \mid<10^{\circ}
\end{array},\right. \\
& R(t)=\sqrt{\left(X(t)-X_{K T}\right)^{2}+\left(Y(t)-Y_{K T}\right)^{2}} ;
\end{aligned}
$$

$X(t), Y(t)$ - current vehicle coordinates in the local coordinate system;

$X_{K T}, Y_{K T}$ - Planned coordinates of the control point in the local coordinate system; Course $(t)$ - current vehicle angle of the vehicle;

Course_CP - calculated vehicle angle of the vehicle at the control point.

An example of the behavior of the analyzed parameters is given in figures 4 and 5 [8,9]. 


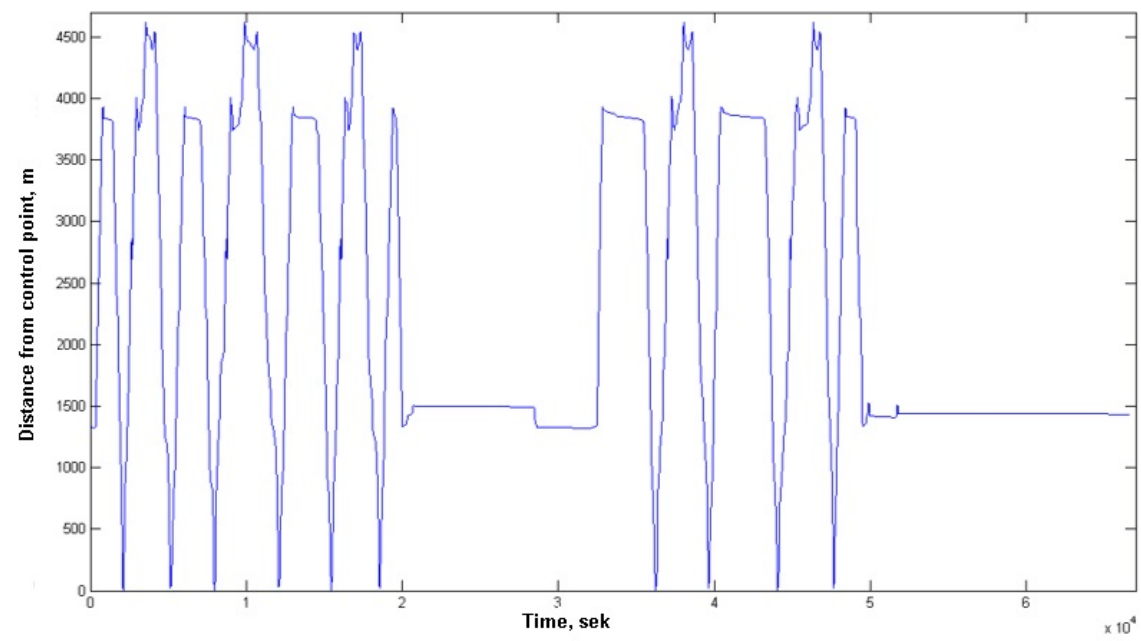

Fig. 4. The distance between the vehicle moving along the route and the control point, as a function of time.

From figures 4 and 5, it is clear that the availability of data on the heading angle makes it possible to identify which of the minima of the function of the distance to the reference point corresponds to a given direction of motion. The result of determining the time of passage of the control point is given in Table. 2. The table shows:

- checkpoint travel time;

- realized course angle;

- Evaluation of the speed of the vehicle at the moment of passage of the control point $[10]$.

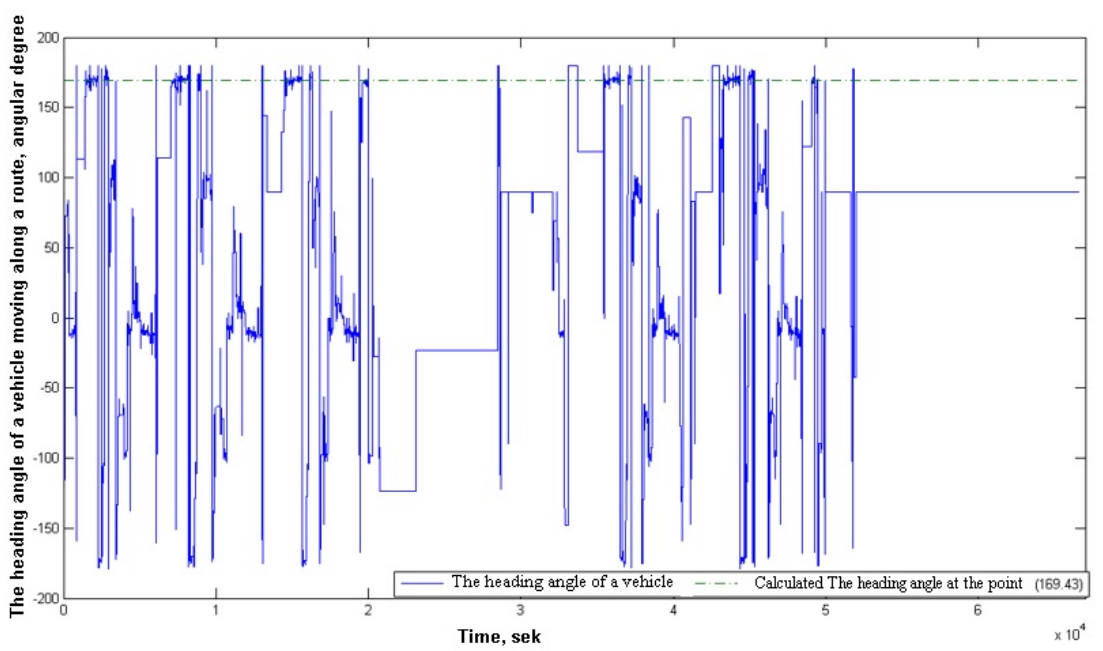

Fig. 5. Moving along a route, as a function of time.

2. To ensure efficient processing of information, it is necessary to fulfill two basic requirements, which must be provided by the software of on-board equipment, in this case software of the firm "SHTRIKH", namely:

- Ensure data acquisition with discreteness no more than $1 \mathrm{sec}$;

- the fullness of all the provided fields of the information message of the tracker. 
Table 2. Checkpoint travel time and traffic characteristics.

\begin{tabular}{|c|c|c|}
\hline $\begin{array}{c}\text { Time from the beginning of } \\
\text { the movement along the route, } \\
\text { sec }\end{array}$ & Course angle, ang. degree & Speed, m/s \\
\hline 2118 & 165,851443857380 & 0,965128100084491 \\
\hline 13846 & 170,867113429434 & 1,33760429525804 \\
\hline 28772 & 168,609388867566 & 2,26955223493185 \\
\hline 70336 & 170,510136761690 & 1,27046240338995 \\
\hline 85960 & 167,615743115747 & 1,38385763260838 \\
\hline
\end{tabular}

Table. 2 an example of real data shows that the discreteness of the registered data frames varies and reaches a maximum of 21 seconds. On the other parts of the track variations of the discreteness of the times from one second to several tens of seconds were observed, and in some cases of hours, which is most likely due to the turn off of the tracker and does not fall under the category of data skipping.

With such large passes in the data logging for estimating the characteristics of the traffic along the route, it is most rational to select control points on the sections of uniform motion, that is, in conditions when interpolation will not have a significant effect on the result [11].

3. During the movement along the route the vehicle repeatedly passes in the immediate vicinity of the control point, which allows estimating the time spent on the route and its dependence on external conditions, primarily related to the time of the day, the days of the week, etc.

If one of the stops or any other waypoint is selected as a control point, the time between two consecutive passes of this checkpoint may include the time of a long parking of the vehicle at the final point of the route. In this case, a real estimate of the duration of the route is estimated as the difference in the time interval between two consecutive passes of the control point and the parking time of the vehicle at the final point:

$$
T_{n, k}\left(\tau_{i}\right)=t_{n, k, i}-t_{n, k, i-1}-\Delta t_{n, i},
$$

$t_{n, k, i}, t_{n, k, i-1}$ - the times of two consecutive passages of the control point, chosen by condition

$$
\frac{t_{n, i}+t_{n, i-1}}{2} \in\left[\tau_{i}-d \tau, \tau_{i}+d \tau\right]
$$

$\tau_{i}$ - the average time of the averaging interval to which the parameter is estimated;

$n$ - vehicle identifier on the route;

$d \tau$ - half-width of the data averaging interval;

$\Delta t_{n, i}-$ the parking time at the final point of the route in the interval $\left[t_{n, i-1}, t_{n, i}\right]$.

The average duration of a route along a route in a given time interval is determined by averaging the data for all vehicles along the route:

$$
T\left(\tau_{i}\right)=\frac{1}{N} \cdot \sum_{n=1}^{N} T_{n}\left(\tau_{i}\right),
$$

$\Delta t_{n, i}$ is defined as the difference between the times of the end and start points within a given interval for which the criterion:

$$
\left\{\begin{array}{c}
R(t)<\frac{D_{\mathrm{K} \Pi}}{2} \\
V(t)=0
\end{array} .\right.
$$

Distance to the central point of the final point of the route:

$$
R(t)=\sqrt{\left(X(t)-X_{K \Pi}\right)^{2}+\left(Y(t)-Y_{K \Pi}\right)^{2}},
$$


$D_{\text {КП }}$ - the maximum size of the site of the final point;

$V(t)$ - vehicle speed.

\section{Conclusion}

When developing a new scheme of public transport, one of the main indicators is the formation of data on the turnover time on the flight and the time of arrival at each of the stops. To solve the task, data is generated about each stopping point on the route, indicating the boundaries of the stopping point in the coordinates [8].

This approach allows you to form any route from already finished areas, to reveal the minimum and maximum speed, i.e. get all the initial data for the formation of the register and the system of forecasting the arrival at each of the stops of public transport (fig. 6).

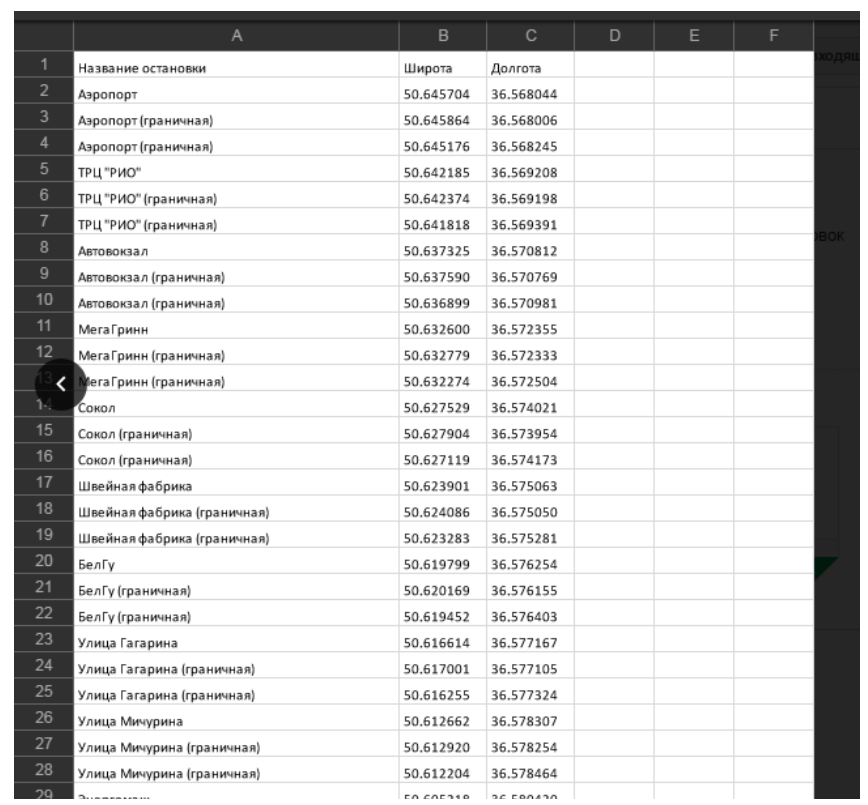

Fig. 6. Data on the location of stops on the route and their boundaries.

\section{References}

1. http://gis-lab.info/projects/osm-export.html (2017)

2. http://wiki.openstreetmap.org/wiki/User:Trolleway/ (2017)

3. V.Yu. Andrianov, GIS in Transport, ArcReeview., 1 (64), pp.12-14, www.gis-lab.info (2013)

4. A.M. Lukyanov, A.E. Borovskoy, V.M. Polyakov, E.I. Yakovleva, On some issues of using navigation systems to determine the life cycle of highways. Technique and technology of transport, 1, pp. 26-31 (2016)

5. I.A. Novikov, A.E. Borovskoy, S.I. Sokorev, E.I. Glushchenko, Analysis of dynamic parameters of traffic flows generated by urban agglomeration objects. In the collection: Regional Scientific and Technical Conference on the results of oriented fundamental research on interdisciplinary topics, conducted by the Russian Foundation 
for Basic Research and the Government of the Belgorod Region, a collection of reports, pp. 245-255 (2016)

6. A.E. Borovskoy, S.I. Sokorev, I.A. Novikov, Creation of exact models of transport streams on the basis of geoinformation data In the collection: Information technologies and innovations in transport materials of the 2nd International Scientific and Practical Conference. Under the general editorship of A.N. Novikov, pp. 10-19 (2016)

7. V.S. Korolyuk, N.I. Portenko, A.V. Skorokhod, A.F. Turbin, A handbook on probability theory and mathematical statistics. M .: Science, 640 p. (1985)

8. K.N. Arkatova, A.E. Borovskoy, E.I.Glushchenko, V.E. Kharuzin, Improving road safety through trajectory analysis of the movement of route vehicles. In the collection: Modern automotive materials and technologies (SAMIT-2016), a collection of articles of the VIII International Scientific and Technical Conference. Executive Editor E.V. Ageyev, pp. 13-22 (2016)

9. L.G. Bolshedvorskaya, Single transport system. Moscow: MSTUGA (2008)

10. Saul Wordworth. Will and sentiment: the automated road to heaven / Saul Wordworth, Traffic Technology International, October / November 2006, pp. 54-58 (2006)

11. A.E. Gorev, K. Bettger, A.V. Prokhorov, R.R. Gizatullin, Transport modeling , 1 st edition. SPbGASU. SPb .: SPbGASU, 30, 168 (2015) 